\title{
CONSTRUCTION OF A WORD BAG MODEL TO DETECT PLAGIARISM IN THE MATLAB LANGUAGE
}

\author{
SIR-ALEXCI SUAREZ ${ }^{1}$, THOMAS EDISON GUERRERO² \& ALBERT MIYER SUAREZ ${ }^{3}$ \\ 1, 2 Engineering Faculty, University Francisco of Paula Santander Ocaña, Colombia. \\ ${ }^{3}$ Faculty of Engineering and Architecture. University of Pamplona, Colombia.
}

\begin{abstract}
A method is presented for building a word bag by extracting tokens from Matlab-coded programs, where each token is labeled according to a value that is assigned as the file is read, and its value varies according to the number of times it is in the program. The levels of plagiarism type 1, 2 and 3 are mainly analyzed, since they are the most used in the academic field. The results show that plagiarism can be detected with programs when using Level 2.
\end{abstract}

KEYWORDS: Plagiarism, Matlab, bag of words, histogram of words

Received: Dec 08, 2020; Accepted: Dec 28, 2020; Published: Jan 07, 2020; Paper Id.: IJMPERDDEC202074

\section{INTRODUCTION}

The copyright allows to protect different documents and works, avoiding the economic loss that entails to the authors and companies that have developed the products. From the academic point of view, we try to avoid based on academic recommendations or sanctions. Plagiarism can be classified according to Rojas (2012) as: direct, inadequate use of paraphrases, complex using some reference, loose quotes, paraphrasing, self-plagiarism; the latter is committed when the appearance of a work is changed and it is presented as if it were another one. In this context, there is software (De La Cruz Vargas et al., 2016; Kashkur, Parshutin, y Borisov, 2010; Shkodkina y Pakauskas, 2017) that can detect plagiarism in documents such as: plagium, Turniti, PlagScan; which are based on vector space models, word bags, local and global structure, as well as semantic aspects (Sánchez-Vega, 2016). The above tools can be effective if they analyze Word style documents, but they are not very efficient when analyzing source code of programming languages; the main reason is that two words in a text are the same when written identically, but in programming they can be different but they are the same words or variables defined by the programmer. To detect plagiarism in a program is used the method of bags of words (BOW) which is to determine the number of tokens ignoring the order in the program and can be classified detection in 7 levels (Picazo-Alvarez, Villatoro-Tello, Luna-Ramírez, y Jaimez-González, 2014): change of expressions, program instructions, combination of functions, position of variables, change of identifiers, change of comments and no change - exact copy.

The work in this field is not only based on the source code but also on the suspicious behavior of each student (Ljubovic y Pajic, 2020)e.g. using and saving in the cloud data of each student when analyzing the number of compilations, the length of the program, the deleted and modified lines, and the time in making a program are parameters that can attract attention when there are values that are outside the normal data of a programmer. It is also possible to extract the tokens of each program and find a match with different languages, this can happen when using a program which is taken to another language in such a way that the plagiarism goes unnoticed (Karnalim, 2020). Also 
Karnalim (2017) proposes that with 35 characteristics you can find acceptable results and found that the most used characteristics were the change of messages and blank spaces with a high total of attacks in the Phyton language.

Due to the complexity of detecting plagiarism in a programming language, most tools work exclusively with one language; that's why we propose language independent libraries as plagiarism (Franclinton y Karnalim, 2019), where you try to order the tokens you find in different positions by means of three panels: the first and second panels show the repeated lines and the last one the amount found, with results that allow to serve as an assistant to reduce the tasks of code observation.

$\mathrm{N}$-grams are used as probabilities to find matching tokens (Burrows y Tahaghoghi, 2007; Jimenez, Cordy, Le Traon, y Papadakis, 2018)and are used to achieve high efficiency in plagiarism control). BOW-based methods allow the use of statistics to find similar instructions, and consists of extracting the amount of tokens and grouping them into a given value using a histogram (Zhang, Jin, y Zhou, 2010).

The objective of this work is the construction of a BOW-based model that allows the identification of plagiarism in Matlabcoded programs by tagging the tokens for statistical analysis.

\section{METHODOLOGY}

When analyzing the levels of complexity of plagiarism in a program we find the 7 levels proposed by Faidhi and Robinson (1987) of which the methodology tries to find fraud on levels 1, 2 and 3 which are the most used by students with little knowledge of programming (see Figure 1).

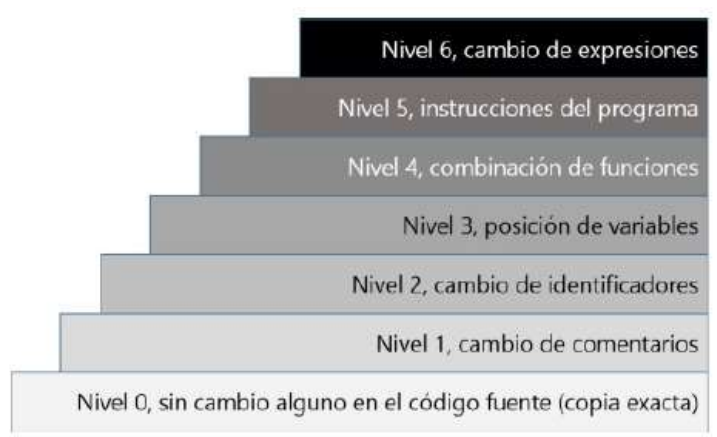

Figure 1: Complexity levels of plagiarism (Picazo-Alvarez et al., 2014, p. 47).

The level 1 is the change of comments and is where most changes are detected when using a source code that is not of own authorship; while the change of identifiers is used by most students with little knowledge in the program and the position of variables is made by expert programmers who try to pass the program through a new one.

\subsection{Token Extraction}

Each token is extracted from the program code and stored in a cell array, in Figure 2 an example of code is shown and in table 1 you can see how it is stored in the cell array.

if $\mathrm{ca}==0$
return;
end




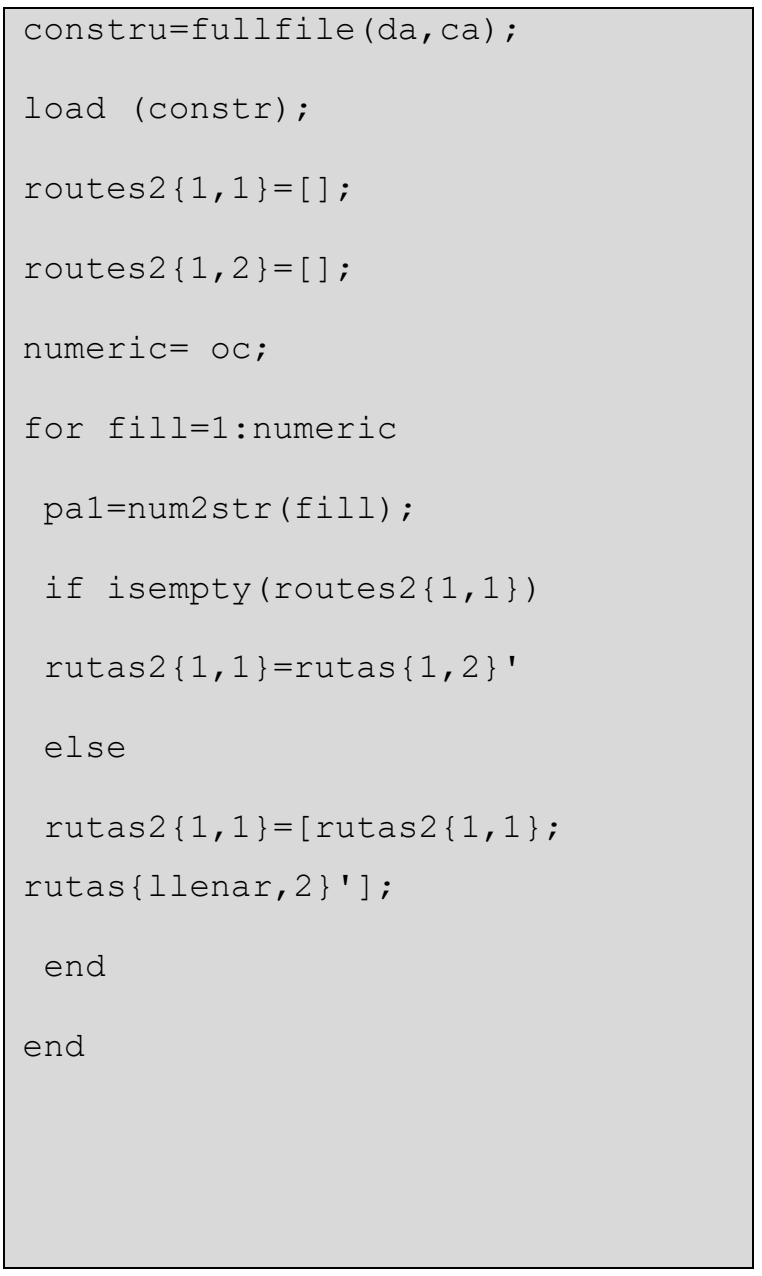

Figure 2: Source code 1.

\section{Table 1: Token Removal}

\begin{tabular}{|l|l|l|}
\hline \multicolumn{1}{|c|}{ Index } & Tokens & Line \\
\hline 1 & if & 1 \\
\hline 2 & ca & 1 \\
\hline 3 & Return & 2 \\
\hline 4 & End & 3 \\
\hline 5 & Constru & 4 \\
\hline 6 & Fullfile & 4 \\
\hline 7 & Give & 4 \\
\hline 8 & ca & 4 \\
\hline 9 & Load & 5 \\
\hline 10 & Constru & 5 \\
\hline 11 & Routes2 & 6 \\
\hline 12 & Routes2 & 7 \\
\hline 13 & Numerical & 8 \\
\hline 14 & Oc & 8 \\
\hline 15 & For & 9 \\
\hline 16 & Fill out & 9 \\
\hline 17 & Numerical & 9 \\
\hline 18 & Pa1 & 10 \\
\hline 19 & Num2str & 10 \\
\hline 20 & Fill out & 10 \\
\hline 21 & If & 11 \\
\hline
\end{tabular}




\begin{tabular}{|l|l|l|}
\hline 22 & isempty & 11 \\
\hline 23 & Routes2 & 11 \\
\hline 24 & Routes2 & 12 \\
\hline 25 & Routes & 12 \\
\hline 26 & Else & 13 \\
\hline 27 & Routes2 & 14 \\
\hline 28 & Routes2 & 14 \\
\hline 29 & Routes & 15 \\
\hline 30 & Fill out & 16 \\
\hline 31 & End & 17 \\
\hline 32 & End & 18 \\
\hline
\end{tabular}

Any source code is done with the same extraction as above.

\subsection{Token labels}

Each one of the reserved words or variables used is labeled, if any of them is repeated only the first one is labeled, remaining as shown in table 2 .

Table 2: Labels

\begin{tabular}{|c|c|}
\hline Label value & Tokens \\
\hline 1 & if \\
\hline 2 & ca \\
\hline 3 & Return \\
\hline 4 & End \\
\hline 5 & Constru \\
\hline 6 & Fullfile \\
\hline 7 & Give \\
\hline 8 & Ca \\
\hline 9 & Load \\
\hline 10 & Routes 2 \\
\hline 11 & Numerical \\
\hline 12 & Oc \\
\hline 13 & For \\
\hline 14 & Fill out \\
\hline 15 & Pa1 \\
\hline 16 & Num2str \\
\hline 17 & Isempty \\
\hline 18 & Routes \\
\hline 19 & Else \\
\hline
\end{tabular}

\subsection{Construction of BOW}

The BOW is constructed by counting the number of times that a word is repeated taking into account the value of the label, if we select IF, END, ROUTES2 and NUMERICAL we can see that it creates a histogram with the number of times it appears (See Fig. 3). Finally, a table is built with the quantification and number of times of each token, so later we can apply the correlation with another program (see Table 3).

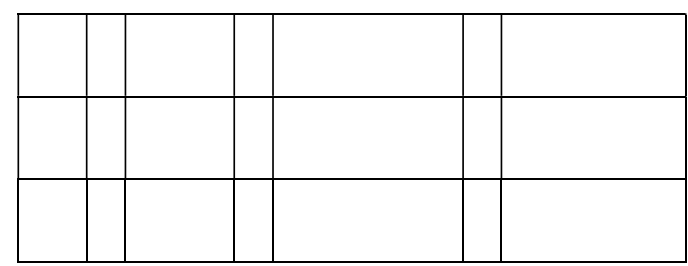




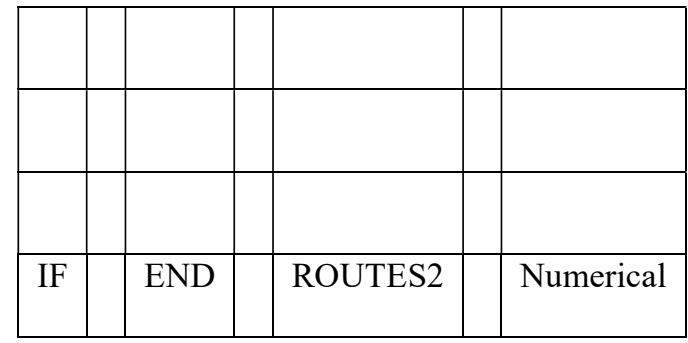

Figure 3: Number of times of tokens

Table 3: BOW Construction

\begin{tabular}{|l|l|l|}
\hline \multicolumn{1}{|c|}{ Label value } & Tokens & Quantity \\
\hline 1 & if & 2 \\
\hline 2 & ca & 1 \\
\hline 3 & Return & 1 \\
\hline 4 & End & 3 \\
\hline 5 & Constru & 2 \\
\hline 6 & Fullfile & 1 \\
\hline 7 & Give & 1 \\
\hline 8 & Ca & 1 \\
\hline 9 & Load & 1 \\
\hline 10 & Routes2 & 6 \\
\hline 11 & Numerical & 2 \\
\hline 12 & Oc & 1 \\
\hline 13 & For & 1 \\
\hline 14 & Fill out & 3 \\
\hline 15 & Pa1 & 1 \\
\hline 16 & Num2str & 1 \\
\hline 17 & Isempty & 1 \\
\hline 18 & Routes & 2 \\
\hline 19 & Else & 1 \\
\hline
\end{tabular}

To compare the effectiveness of the method, three source codes that presented the same solution to the problem were compared and the correlation between them was made. Because the codes did not resemble each other by changing the name of variables, an overlap was made so that the variables were changed to var1, var2, var3, etc. While the reserved words were left with the same extraction token.

\section{RESULTS}

The 3 codes were overlapped, for example code 1 is represented by table 4 , where we can replace the tokens by other tokens that allow an equality between the tokens of other programs.

Table 4: BOW Overlay

\begin{tabular}{|c|c|c|}
\hline Label value & Tokens & Quantity \\
\hline 1 & if & 2 \\
\hline 2 & VAR1 & 1 \\
\hline 3 & Return & 1 \\
\hline 4 & End & 3 \\
\hline
\end{tabular}




\begin{tabular}{|c|c|c|}
\hline 5 & VAR2 & 2 \\
\hline 6 & Fullfile & 1 \\
\hline 7 & VAR3 & 1 \\
\hline 8 & VAR4 & 1 \\
\hline 9 & Load & 1 \\
\hline 10 & VAR5 & 6 \\
\hline 11 & VAR6 & 2 \\
\hline 12 & VAR7 & 1 \\
\hline 13 & For & 1 \\
\hline 14 & VAR8 & 3 \\
\hline 15 & VAR9 & 1 \\
\hline 16 & Num2str & 1 \\
\hline 17 & Isempty & 1 \\
\hline 18 & VAR10 & 2 \\
\hline 19 & Else & 1 \\
\hline
\end{tabular}

In this way it is not interesting to make changes to the identifiers since by superimposition you will find those that are repeated using correlation.

In Figure 4 you can see the program code 2, although a change of level 2 has been made by the students the program will detect it because the BOW will end up being the same

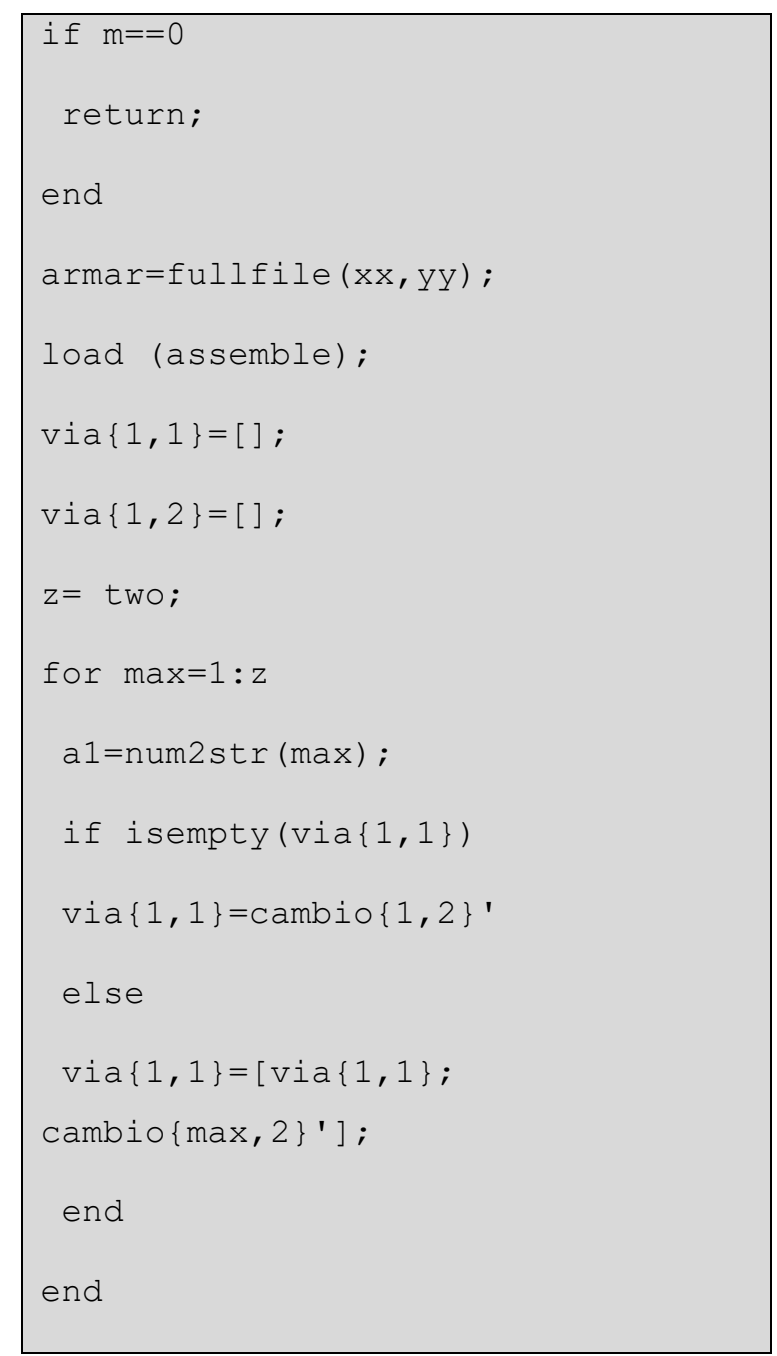




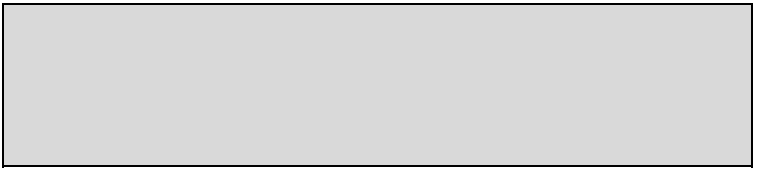

Figure 4: Source code 2

When you compare the instruction of code 1 with that of code 2 you will find that they are identical (see Figure 5)

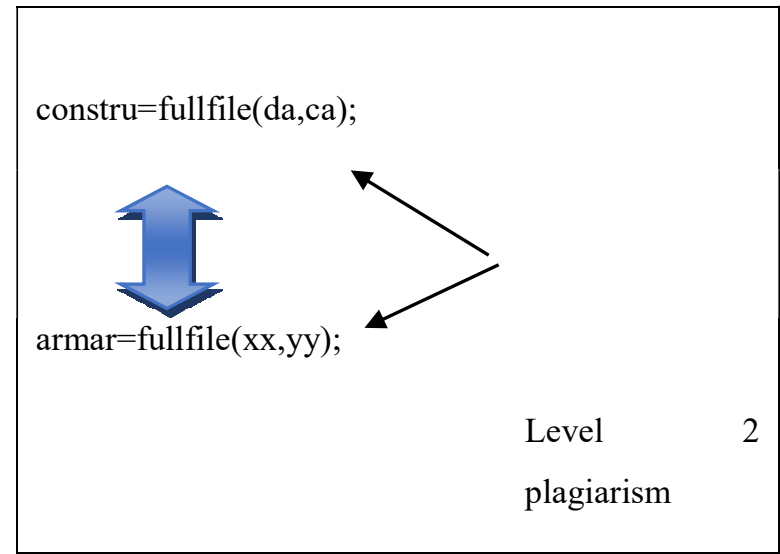

Figure 5: Level 2 plagiarism.

In table 5 , it can be determined that programs 1 and 2 maintain a correlation of 1 with which is level 2 plagiarism and there is also level 6 plagiarism because they end up changing expressions (Equation 1). Between program 1 and 2 there is no correlation with program 3 so no level plagiarism has been found (see table 5).

$$
\rho(A, B)=\frac{1}{N-1} \sum_{i=1}^{N}\left(\overline{\frac{A_{l}-\mu_{A}}{\sigma_{A}}}\right)\left(\overline{\frac{B_{l}-\mu_{B}}{\sigma_{B}}}\right)
$$

Table 5: Correlation

\begin{tabular}{|l|l|l|}
\hline 1 & 1 & 0.23 \\
\hline 1 & 1 & 0.14 \\
\hline 0.23 & 0.14 & 1 \\
\hline
\end{tabular}

\section{CONCLUSIONS}

The construction of a bag of words and the quantification by replacing the identifiers of each program by common identifiers allows to determine when there is level 2 plagiarism, independently if the programmer has changed the identifiers, so that plagiarism can be found among programs submitted by students who try to submit a program totally or partially without being the author. It is only determined when the programs have been changed by level 2 , and the level 1 belonging to the interface change has not been determined.

\section{REFERENCES}

1. Burrows, S., y Tahaghoghi, S. M. M. (2007). Source code authorship attribution using n-grams. ADCS 2007 - Proceedings of the Twelfth Australasian Document Computing Symposium. 
2. De La Cruz Vargas, J., Huamán-Guerrero, M., Baldeon-Martinez, P., Torres-Otárola, C., Luna-Muñoz, C., and CorreaLopez, L. (2016). Application of the Turnitin software and its final similarity index, as an indicator of originality in human medicine theses. Journal of the Faculty of Human Medicine, 16. https://doi.org/10.25176/RFMH.v16.n2.666

3. Faidhi, J. A. W., y Robinson, S. K. (1987). An empirical approach for detecting program similarity and plagiarism within a university programming environment. Computers \& Education, 11(1), 11-19. https://doi.org/10.1016/03601315(87)90042-X

4. Franclinton, R., y Karnalim, O. (2019). A Language-Independent Library for Observing Source Code Plagiarism. Journal of Information Systems Engineering and Business Intelligence, 5(2), 110-119. https://doi.org/10.20473/jisebi.5.2.110-119

5. Jimenez, M., Cordy, M., Le Traon, Y., y Papadakis, M. (2018, septiembre 1). On the Impact of Tokenizer and Parameters on N-Gram Based Code Analysis. 437-448. https://doi.org/10.1109/ICSME.2018.00053

6. Karnalim, O. (2017). Python Source Code Plagiarism Attacks on Introductory Programming Course Assignments. Themes in Science and Technology Education, 10, 17-29.

7. Karnalim, O. (2020). TF-IDF Inspired Detection for Cross-Language Source Code Plagiarism and Collusion. Computer Science, 21. https://doi.org/10.7494/csci.2020.21.1.3389

8. Kashkur, M., Parshutin, S., y Borisov, A. (2010). Research into Plagiarism Cases and Plagiarism Detection Methods. J. Riga Technical University, 42, 138-143. https://doi.org/10.2478/v10143-010-0055-1

9. Ljubovic, V., y Pajic, E. (2020). Plagiarism Detection in Computer Programming Using Feature Extraction From UltraFine-Grained Repositories. IEEE Access, 8, 96505-96514. https://doi.org/10.1109/ACCESS.2020.2996146

10. Picazo-Alvarez, R., Villatoro-Tello, E., Luna-Ramírez, W.-A., and Jaimez-González, C. (2014). Support Tool for the Detection of Source Code Reuse. Research in Computing Science, 73, 45-57. https://doi.org/10.13053/rcs-73-1-3

11. Rojas, M. E. (2012). Plagiarism in academic texts. Educare Electronic Journal, 16(2), 55-66. https://doi.org/10.15359/ree.16-2.3

12. Sánchez-Vega, J. F. (2016). Identification of paraphrased plagiarism incorporating structure, meaning and style of texts (PhD Thesis). PhD thesis, National Institute of Astrophysics, Optics and Electronics.

13. Shkodkina, Y., y Pakauskas, D. (2017). Comparative Analysis of Plagiarism Detection Systems. Business Ethics and Leadership, 1, 27-35. https://doi.org/10.21272/bel.1(3).27-35.2017

14. Zhang, Y., Jin, R., y Zhou, Z.-H. (2010). Understanding bag-of-words model: A statistical framework. International Journal of Machine Learning and Cybernetics, 1, 43-52. https://doi.org/10.1007/s13042-010-0001-0 